\title{
Title: Negotiating topic changes: native and non-native speakers of English in conversation
}

\author{
Muna Morris-Adams, Aston University
}

\begin{abstract}
There is a tendency to view conversations involving non-native speakers (NNSs) as inevitably fraught with problems, including an inability to handle topic management. This article, in contrast, will focus on effective topic changes made by non-native speakers during informal conversations with native speakers of English. A micro-analysis of ten conversations revealed several ways of shifting conversational topics; however, the article concentrates on those strategies which the participants used to effect a particular type of topic move, namely 'marked topic changes', where there is no connection at all with previous talk. The findings show how these topic changes were jointly negotiated, and that the non-native speakers' contributions to initiating new topics were competently managed.
\end{abstract}

Keywords: non-native speakers, informal conversations, intercultural communication, topic management, topic change

Es gibt eine Tendenz, Gespräche mit Nichtmuttersprachlern als problematisch anzusehen, besonders die Unfähigkeit, Themenwechsel zu beherrschen. Dieser Artikel im Gegensatz fokussiert auf effektive Themenwechsel von Nichtmuttersprachlern in informellen Gesprächen mit englischen Muttersprachlern. Eine Mikroanalyse von zehn Gesprächen zeigt mehrere Arten von Themenwechsel; Dieser Artikel konzentriert sich vor allem auf jene Strategien, die die Teilnehmer für eine besondere Art von Themenwechsel verwenden, nämlich jene wo es überhaupt keine Verbindung zu früheren Themen gibt. Die Resultate zeigen, wie diese Themenwechsel gemeinsam verhandelt werden, und dass die Nichtmuttersprachler Kompetenz zeigen, neue Themen einzuführen.

Keywörter: Nichtmuttersprachler, informelle Gespräche , Themenbereich wechseln, Themenmanagement, interkulturelle Kommunikation

\section{Introduction}

Wong's observation (2005:172) that "Ways of staying in a NS-NNS conversation or of maintaining the conversational flow may be more difficult and more 'noticeable' than in NS-NS interaction" reflects the perspective often found in research into native-non-native speaker (NS-NNS) interactions. It is, for example, telling of the way NNSs are perceived that they are referred to by some researchers as 'not-yet-competent' speakers (Egbert 2005; Wong 2005) and compared with 'proficient' or 'expert' speakers, usually taken to mean native speakers of English. The connotation of linguistic inferiority is similarly implied in the commonly used terms: native and non-native speaker, which fail to take into account that large numbers of non-native speakers of English are able to participate successfully and competently in intercultural communications. It is clear therefore that any terminology will have to employed with this caution in mind. The terms NS and NNS have, in spite of their somewhat problematic nature, been used in this article, primarily on the basis that no suitable 
alternatives exist, but also with the caveat that NNSs should not automatically be considered as 'deficient' speakers.

Kurhila (2007:143) noted that "Authentic NS-NNS interaction with its characteristics and problems has been studied relatively little and only very recently", and, as the quote implies, much of the research has tended to focus on problems rather than successes in intercultural encounters. Topical continuity, for example, is thought to be difficult to achieve for NNSs with the apparent result that such conversations may appear disjointed and incoherent, and may contain frequent changes of topics. Meierkord (2000:8) found that NNSs in a lingua franca context not only tended to prefer safe topics, but also tended to deal with them superficially, employing largely short turns. Richards (1990:70), similarly, claimed that "The inability to take up long turns in a conversation is a feature of many second language speakers, who keep short turns and appear to be less than collaborative conversational partners." The ability of NNSs to deal with certain dimensions of discourse, such as the management of topic organisation in conversations, has also been investigated by Itakura (2002), Iwata (2010) and Viswat and Kobayashi (2008), all concluding that this is an area of difficulty for NNSs. Schwienhorst (2004:35) comments that "..some researchers on nativespeaker/non-native speaker discourse have claimed that native speakers initiate the majority of topics, and that non-native speakers preferably initiate a topic by using questions." He cites the influential studies by Long that appeared to show that "topics are initiated to a large extent by NSs (Long, 1983b, p.133)", and that "NSs accept more readily new and abrupt topic introductions by NNSs (Long, 1981b, pp.135-136)". Two additional points made by Long are relevant here, namely that NSs use framing "to mark closure of old topics and introduction of new ones", and that they "accept unintentional topic-switch by NNS". The overall perception, then, is that NNSs struggle with most aspects of topic management in conversations.

The findings presented in this article are part of a larger study which explored the key issues of whether NS-NNS discourse is inevitably problematic discourse, and, if it is not, how successful interactions are accomplished. The context, therefore, is one which has been comparatively under-researched. The key question which this article explores is whether the NNSs tend to use more non-coherent or sudden, disjunctive topic changes, and if so, what effect this may have on the topical development of the conversations.

\section{Topic management}

Broe (2003:181) states that "...the achievement of conversational coherence is one of the main tasks speakers face when engaging in conversations". This coherence is primarily achieved through the turn-taking system, where one turn will in some manner be related to a previous turn, in terms of referents, lexis, and topical content. The interpretation of an utterance is thus crucial for the formulation of any next utterance; in other words, coherence in talk is created through the interplay of participants as hearer and speaker, and becomes therefore an interactional achievement. According to Bublitz (1999:2)

..coherence is not a state, but a process, helped along by a host of interacting factors situated on all levels of communication (from prosodic variation to textual organisation, from topic progression to knowledge alignment).

Coherence is therefore strongly implicated in topics shifts, a term which is used to cover all changes in topical direction. Topic transitions occur when topics are shifted in a gradual and coherent manner, resulting in a smooth conversational flow over one or more turns. Topic change, in contrast, occurs where no apparent coherence relations are evident, in 
other words, a new topic is introduced which has no lexical or propositional link with aspects of immediately preceding topics. On this basis it becomes possible to identify topic changes in conversations. As Brown and Yule (1983:69) point out "There do exist ways of identifying the boundaries of stretches of discourse which set one chunk of discourse off from the next."

A number of strategies which signal impending topic change have been identified. While explicit signals like By the way and Anyway, together with other formulaic expressions, may be used in such cases, it is, in the words of Brown and Yule (1983:69) more often the case that "... speakers do not often provide such explicit guidelines to help the analyst select chunks of discourse for study." What we get instead tends to be a gradual closing down of the current topic, followed by a negotiated introduction of a new one. Topic change, in other words, is frequently a two-stage process, consisting of topic closure and topic initiation. Geluykens (1997:36 in Bublitz et al 1999) comments that

"... once a new topic has been introduced, or rather proposed for introduction, by a participant, then it needs to be negotiated and acknowledged by the other participant(s) in order to become integrated into the conversation ".

The different ways in which participants collaborate in closing down a topic have been investigated by several researchers. Abu-Akel (2002:1790-1791), for example, points out that "Several discourse operants are often used to mark topic boundaries." He mentions specific marking devices which can function as possible indicators of topic boundaries, such as prosodic features, hesitancy, and Uh... or Well + New Topic. Howe (1991:1) produced an overview of those "topic-ending utterances which mark disjunctive topic changes." She found that "Summary assessments and pauses seem to be the most common such indicators and were also most commonly found together, with pauses following summary assessments." (ibid:8). In addition to summary assessments and pauses as topic-ending indicators, she also includes acknowledgement tokens, such as yeah, okay, hmm; repetition and laughter. Jefferson (1984) and Holt (2010) also found laughter to play a key part in topic terminations.

There would seem to be three main reasons why a topic change might be initiated. Firstly, it is inevitable that a particular topic will run its course in a conversation; there comes a point when no further useful contributions can be made, and a topic change most commonly occurs when the current topic has run out of steam (Maynard 1980). Secondly, a topic change might be occasioned by some event external to the conversation, which requires immediate attention, such as a child crying, and this may provoke a comment unrelated to the current topic. Thirdly, a conversation-internal event may need attention and disrupt the flow of the current topic, for example a potential misunderstanding and need for clarification. We can therefore talk about two distinctly different types of topic change, namely one which follows the pattern of gradual closure, and another where the topic may be shifted in a more abrupt or sudden manner.

\section{Research context and data}

International students at a UK university were invited to volunteer to record informal conversations with English friends, which resulted in ten conversations conducted in a variety of social contexts. The recordings varied in length from 7 to 35 minutes, with a total of 3 hours of talk. No specifications about topics or format were given, nor was the researcher present, and they can therefore be considered examples of natural interactions.

The NNS participants had been living in England for periods varying from 10 weeks to 8 months at the time of the recordings, and their language levels ranged from intermediate 
to advanced. The two male participants are French; the females are German, Turkish-German, French, Slovakian, Belgian and Japanese. A wide range of nationalities is represented, which makes it different from most research into NS-NNS interaction, where the NNS participants tend to be a homogenous group. This variety of nationalities should contribute to a richer picture of who the non-native speaker is, and what he or she can accomplish in a foreign language.

During initial transcription and analysis of the conversations topic management emerged as a feature of interest. Further micro-analysis revealed topics to be a major coherence-organising element in the conversations, and that coherence relations played a crucial part in the strategies used for ensuring effective topic organisation. This focus on coherence in turn ties in with the overall perspective of the research, namely that non-native speaker discourse is not necessarily 'incoherent' discourse.

Since coherence relations are implicated in the distinctions between different topic moves, this formed a major analytical category, with moves being characterised according to the degree and nature of those coherence relations. The classification of types of coherence relations has drawn on studies by Ainsworth-Vaughn (1992), Svennevig (1999) and Tryggvason (2004), who all propose that topical coherence operates on a scale from noncoherent to stronger or weaker degrees of coherence.

The main distinguishing feature was whether or not topic initiations showed a connection to previous talk, which linked with the definitions of topic change and topic transition respectively, namely whether there was no connection at all, or whether there was a partial connection. Topic transitions predominated in the data (see to be inserted 2014), but the focus in this article is exclusively on topic changes.

Maynard (1980:264) says of topic changes that "they are unrelated to the talk in prior turns in that they utilize new referents, and thus they implicate and occasion a series of utterances constituting a different line of talk"; in other words, topic changes contain no propositional or lexical connections with immediately previous talk. Further analysis of the data revealed two distinctly different types of topic change: non-coherent or marked topic changes which show no connections with previous talk, but which always follow signals of closure of the previous topic, and disjunctive topic changes which are initiated without closure of the current topic, and the change to a new topic is therefore sudden and abrupt. Extracts from the conversations will show how the NNSs managed both types of topic change.

\section{Findings}

Topic changes are in fact relatively rare in these conversations. Two of the conversations contain no topic changes at all, and in the remaining eight conversations only a total of 29 topic changes were identified. Eight of them occurred in one comparatively short conversation. In contrast, one of the longest conversations has only one instance of a topic change. An almost equal number of topic changing initiations were performed by NSs (14) and NNSs (15), and there is no evidence, therefore, to indicate that these NNSs are any more likely than their NS partners to change topics frequently or abruptly, nor that they rely on NSs to do the work of introducing new topics. The great majority of topical shifts were effected via topic transitions, meaning that the talk flowed smoothly from one topic to another.

Some of the topic changes were to a large degree context-dependent. In other words, topic organisation was affected partly by other activities which participants were doing concurrently with the talking, such as looking at newspapers, eating lunch and filling in an application form. Two fairly short conversations where participants were engaged in some 
other activity while talking were the ones which contained the greatest number of marked topic changes, and consequently fewer topic transitions.

While the topic changes will be discussed according to specific features which they exhibit, in the context of the very complex processes involved in topic management, watertight categories are rare, and there will inevitably be cases where more than one feature is in evidence.

\section{Marked topic changes}

The following sections will discuss some of the ways in which marked topic changes come about and are jointly managed, but with a particular focus on the part played by the NNSs in getting a new topic introduced and established, and in responding to topic changes initiated by their NS partners.

\section{Pauses and laughter}

Non-verbal signals such as pauses and laughter can be indicators that a topic is being wound down, or mutually brought to a close, and extracts from the data will show how such signals led to or initiated a change in topic. It should be pointed out, however, that such signals do not have to lead to a topic change, and indeed the data showed that they do not invariably do so.

Pauses are one possible signal of impending topic change, and are also likely to be present when the conversation itself is coming towards an end. Overall there were few long pauses in any of the conversations, a sign that the participants were able to keep the talk flowing. More often than not pauses were present in conjunction with other signs of impending topic change, for example, reaching mutual agreement on an issue, producing sequential assessments, and quite prominently, instances of laughter.

Pauses were most frequent in the conversation between Pierre and Rose, who were discussing a university application form, and in the following extract we can see an example of a 5-second pause apparently signalling the end of a topic.

\section{Extract $1 \quad$ Pierre (NNS) Rose (NS)}

096 Pierre no I understood that you have to do it (..) as soon as

097 possible

$098 \quad$ (5.0)

099 Rose (( laughs ))

100 Pierre what's wrong ? (( laughing $))$

101 Rose nothing (( laughs ))

102 Pierre you think I think you sound funny?

Following this lapse in the talk, it is Rose's laughter in line 099 which is made the topic of the conversation. In line 100 Pierre attempts to find out what has caused the laughter, as there is seemingly nothing in the immediately preceding talk to have caused amusement. The way he phrases the question may in fact indicate that he is aware of this, as he asks what's wrong? while joining in the laughter. This together with his follow-up question indicates that he is trying to establish a relevant link with what has gone before, thus showing awareness of an expectation of coherence in talk. 
While the laughter in the extract above functioned to generate further talk after a pause, there were other cases where laughter itself was one of the signs which indicated that a topic was in the process of being closed down, where it functioned, in a sense, as a final comment on a topic. Laughter, of course, has many functions in talk: "Laughter can do such conversational work as displaying involvement and interest" (Glenn 2003:264). Stewart (1997:7) identified a meta-linguistic function, where "Laughter helps with the management of conversation serving as a turn-taking cue or a topic-ending indicator" and an evaluative function which can serve, for example, to express an attitude to what has been said, and to display "like-mindedness among speakers." (ibid:5). The extracts below will show how such functions were present at points where topics were closed down. The first one comes from the very beginning of a conversation.

\section{Extract 2 Sara (NNS) Ann (NS)}

007 Sara I just I think it's enough if we just make one one side

008 Ann (xxx)

$009 \quad$ (both laughing)

010 Sara ok eh I don't know (..) what what we can talk about (..) it's quite

011 Ann anything

012 Sara anything well I must say it really is a nice nice area

In the first few lines the friends talk about setting up the equipment and deciding on the duration of the recording. Ann's response in line 008 is not audible, but results in mutual laughter. Following the laughter, Sara in line 010 signals a change in focus by her use of the discourse marker 'Ok', and her follow-up comment seems to contain an implied appeal for topic suggestions. Ann's 'anything' passes the initiative to Sara, who responds with a comment about the area where her friend lives, and this topic leads to further discussion.

In the next example Laura and Claire are looking at a photo of the singer, Rod Stewart, in a tabloid newspaper.

\section{Extract $3 \quad$ Laura (NNS) Claire (NS)}

013 Claire Oh he's horrible isn't he ? He's actually horrible

014 Laura (( laughs )) ( 4.0$)$ What does this say (..) there ?

015 Claire She's going running (..) in Notting Hill

In line 013 Claire sums up her opinion of Rod Stewart, and Laura laughs in response. Laura's laughter in line 014 could be seen as showing appreciation of Claire's comment on the singer, and possibly functioning as a substitute for a verbally expressed agreement or disagreement. There follows a 4 second pause, and then Laura changes the topic by asking a question relating to another item in the newspaper, thus taking responsibility for initiating further talk and for keeping the conversation going.

\section{So and So what....?}

The discourse marker so featured prominently in many of the marked topic changes. Fung and Carter (2007:413) comment that so exemplifies the multifunctionality of discourse markers, and also "their use as a flexible interactional resource in summarizing, marking 
boundaries of talk, switching topic, establishing consequences, etc." They draw particular attention to the structural function, which is

to provide information about the ways in which successive units of talk are linked to each other and how a sequence of verbal activities, the opening, closing, transition, and continuation of topics, are organized and managed (ibid:420).

They also note that so was one of the discourse markers which, in their Chinese learner corpus, was less frequently used by the learners than by native speakers. In the current study it was employed in equal measure by NSs and NNSs, during topic changes at least.

Schriffrin (1987:218) also points to the role of so as a turn-transition device, and shows how it can be used to allocate "interactional responsibility to the hearer" (ibid:256). We can see in the extract below how Fay in line 486 uses So to invite Will to initiate a new topic, and how he offers 'the weather' as a potential topic.

Extract $4 \quad$ Will (NS) Fay (NNS)

484 Will the comic strip but it's very ( ) nasty ( $\operatorname{xxx} \mathrm{xxx})(\mathrm{)}$ but anyway

485 that's magazines and newspapers covered

486 Fay $\rightarrow$ so (...)

487 Will $\rightarrow$ the weather?

488 Fay no it's too=

489 Will =you think it's too cold?

The use of the 'stand-alone' so (Raymond 2004) and a brief pause also follows the closure of a topic in the next extract, where an episode of mutual teasing has just come to an end.

Extract $5 \quad$ Jana (NNS) Dave (NS)

265 Dave you're too lazy anyway and you're a Siebkopf

267 Jana uhm yes I am

268 Dave $\rightarrow$ so $(\ldots)$

269 Jana $\rightarrow \quad$ yeah do you have any brothers and sisters ?

270 Dave two brothers

271 Jana younger than you ?

Dave's so in line 268 could be both a means of summarizing or finalising this episode and of inviting Jana to take the floor and to introduce another matter to talk about. According to Raymond (2004:193), a stand-alone 'so' is "apparently designed to prompt action by its recipient." Jana responds to this prompt by producing first an acknowledgement token, and then asking a personal question. She therefore shows that she understands the interactional function of the discourse marker, and responds appropriately to the challenge of taking responsibility for introducing a new topic.

Where so is combined with a question to initiate a new topic, it then becomes a way of linguistically marking such a change, of explicitly indicating to the hearer that a new topic is being proposed. Questions were by far the most common method of initiating a new topic in marked topic changes, with 18 out of the 29 topic initiations performed by way of questions, and they were employed equally by NSs and NNSs. With respect to topic changes, at least, 
this would indicate that these were symmetrical conversations, with equal rights of participation and topic control equally shared by the participants (Itakura 2001).

A So plus question combination is used by Pierre in the next extract. The topic change in line 034 follows the completion of an adjacency pair, and Pierre's So what..? proposes a new topic.

\section{Extract $6 \quad$ Pierre (NNS) Rose (NS)}

032 Pierre do you want to go for a coffee later ?

033 Rose uh hu (...) uh hu

034 $\rightarrow$ Pierre so what what does your mum (..) think about the applications ?

035 Rose yeah she I mean she liked Exeter but she thinks I should apply to Nottingham as well now

$037 \quad$ Pierre why?

Bolden (2006:670) suggests that "'So' often prefaces utterances that function as proffers of various addressee-centred topics". It is, then, an example of a discursive practice which signals "other-attentiveness", as Bolden calls it (ibid:662), in other words an interest in the conversational partner. Pierre shows some skill at explicitly signalling the change, and at ensuring attentiveness to his partner by proposing a topic which is likely to be of concern to her.

According to Planalp and Tracy (1980:244) speakers may cue the listener in various ways about the context of upcoming information in topic changes in order to save the listener from "the effort in searching for an appropriate context." So is obviously one such clue, but there were instances where additional information was provided prior to a topic-proposing question. An example can be seen in the following extract.

\section{Extract 7}

Jana (NNS) Dave (NS)

$390 \quad$ Dave

so you know my parents always used to say : Dave the

391

392

Jana harder you work the better you'll [do in life

393 Dave and I eh never really listened to them ha (...) yeah

394 Jana yeah that's a shame.

395 Dave $\rightarrow$ so eh listen Christmas is coming up what're you going

396 to buy me for my present ?

397 Jana nothing why should I buy you something ?

Following Jana's teasing assessment in line 394 about Dave not listening to the advice of his parents, Dave signals a change in topic, starting with So. This change is made additionally explicit by the exhortation listen, and then the context is introduced: Christmas is coming up. Once the context has been established, he asks a question related to this event, thus proposing a new topic. A similar example of contextualisation before asking a question comes from the NNS in the next extract, though here the initiation was not immediately successful.

\section{Extract 8}

$028 \quad$ Max

029
Bella (NNS) Max (NS)

'cause in the Guild they play music that's just too cheesy for most people 


\begin{tabular}{|c|c|c|}
\hline 030 & Bella & Yeah it's true \\
\hline 031 & $\operatorname{Max}$ & so in order for people to enjoy themselves they've got to get \\
\hline 032 & & very drunk \\
\hline $033 \rightarrow$ & Bella & (laughs) yeah (xxx xxx) so yesterday eh \\
\hline 034 & Max & I don't think people get that pissed when they go out on Broad \\
\hline 035 & & Street \\
\hline 036 & Bella & You sure? \\
\hline $\begin{array}{l}037 \\
038\end{array}$ & Max & $\begin{array}{l}\text { I'm pretty sure because for one the drinks are much more } \\
\text { expensive }\end{array}$ \\
\hline 039 & Bella & Yeah (..) so they just buy drinks before \\
\hline 040 & $\operatorname{Max}$ & Uh \\
\hline $\begin{array}{l}041 \rightarrow \\
042\end{array}$ & Bella & $\begin{array}{l}\text { Uh (..) Uhm eh yesterday I brought my friend ( } \mathrm{xx} \text { ) too he's } \\
\text { [French }\end{array}$ \\
\hline 043 & Max & [ yeah \\
\hline 044 & Bella & and he he liked the party [obviously \\
\hline 045 & Max & [ uh \\
\hline 046 & Bella & but now he's tired and (.. ) so eh he's asking me that we \\
\hline 047 & & should not be going out tonight. What do you think ? (...) \\
\hline
\end{tabular}

The discussion here is centred on the drinking habits of English students, and Max jokingly suggests that students have to drink in order to tolerate the type of music played in the Students' Guild. In line 033 Bella laughs and expresses agreement. Her additional comment was not audible, but she then attempts to initiate a new topic in line 033, beginning with so yesterday. Her hesitation allows Max to take the floor again, and he continues to talk about drinking. Bella responds appropriately to his comments, and when the topic slows down as evidenced by minimal responses by both parties in lines 040 and 041, Bella reintroduces the topic initiation which she started earlier, this time by repeating the word yesterday. The information about her French friend provides a context for the question in line 047, which asks for Max's opinion. Bella, then, shows her topic management skills on several levels: she uses the discourse marker appropriately to signal a change of topic; she supplies relevant contextual information in preparation for asking a question, and she does not drop the topic in spite of an initially unsuccessful attempt at introducing it. Planalp and Tracy (1980:256) observe that

The most competent types of topic change are those where the context is most salient to the listener, either because the attention is focused there, or because the context is explicitly cued.

We have seen that the NNSs can competently both initiate and respond to topic changes, making fairly skilful use of both the discourse marker so and of questions which engage their partners in continued talk.

\section{Re-initiated topics and setting talk}

Where other activities are taking place concurrent with the talk, we get what Carter and McCarthy (1997:58) call 'language-in-action conversations' or setting talk, "where people do not need to mention directly things which are obvious and right in front of them at that moment." Instead we see greater use of referents like this, that, there, which help to establish the context. Furthermore, it is to some extent the activity which structures the conversation, 
and provides a resource that participants can draw on to keep the talk moving. Topic changes in these contexts showed no local connection at all to the talk or topics in progress, but nonetheless contributed a sense of global coherence by being connected to earlier talk and to the activities which participants were engaged in.

In one of the conversations the themes of the university application form and the recording of the talk were resorted to recurrently throughout the conversation.

$\begin{array}{lll}\text { Extract } & & \text { Pierre (NNS) } \quad \text { Rose (NS) } \\ 028 & \text { Pierre } & \text { uh }(1.0) \\ 029 \rightarrow & \text { Rose } & \text { I think you can do most of this (xxx xxx) address ? } \\ 030 & \text { Pierre } & \text { yeah (xxx xxx) } \\ 031 & \text { Rose } & \text { uh hu }\end{array}$

After the pause Rose returns in line 029 to the topic of the application form, and although there is no immediate connection between this and the previous topic, there is still a global link in so far as this topic is one which runs like a thread through the whole conversation, and references to it are frequent. It is, therefore, a re-initiation of a previous topic, and the meaning is easily retrieved by her partner. Lenk (1998:256) states that "participants in conversation are constantly engaged in processing incoming information towards an understanding of the overall connectedness of parts of discourse", and in the example above topical content may confer a degree of global coherence. The re-initiation of these topics may help to explain the comparatively high number of topic changes in this conversation.

A similar strategy for introducing new topics can be seen in the next two extracts, where the setting and activities provide a topical resource to draw on at various stages in the talk. In extract 10 it is Max's lunch which the NNS employs as a resource.

Extract $10 \quad$ Bella (NNS) Max (NS)

$119 \rightarrow$ Bella Ah so at 3 you're cutting $(\mathrm{xxx})$ your hair $(\mathrm{xxx} \mathrm{xxx})$ Is it good

$120 \quad$ your beans ?

121 Max Uh (...)

122 Bella I don't want to try

123 Max They're mature but the Cheddar cheese isn't very mature

Immediately after a comment which summarises the previous topic, Bella re-introduces a focus on Max's lunch, asking if it is good. Having summarised previous talk, it then becomes legitimate to introduce a new and unrelated topic. Although there is no immediate connection with the topic of Max's haircut, there is a clear link to the on-going activity of eating the lunch, which has been discussed before, and it is therefore a re-initiation.

A tabloid newspaper provided the resource for the introduction of entirely new topics in another conversation. These were not re-initiations of topics, but by virtue of the activity provided a sense of conversational coherence. In Extract 11 Claire's summarising assessment in line 388 that the pizza she has just eaten was 'well tasty' signals closure of the previous topic.

Extract $11 \quad$ Laura (NNS) Claire (NS) 


\begin{tabular}{|c|c|c|}
\hline 388 & Claire & yeah hehe it was well tasty \\
\hline 389 & & $(\ldots)$ \\
\hline $390-$ & Laura & what is that one doing? \\
\hline 391 & & $(\ldots)$ \\
\hline 392 & Claire & he's tackling a wasp nest \\
\hline 393 & Laura & wasp nest ? \\
\hline 395 & Claire & yeah fucking hell look at them all \\
\hline 397 & Laura & uh \\
\hline 398 & & $\begin{array}{l}(\ldots) \\
\text { (Claire sniffs }\end{array}$ \\
\hline 399 & & $(7.0)$ \\
\hline 400 & Claire & I'd want a bit more protection it doesn't look like \\
\hline 401 & & he's wearing that much to me I want full on kind \\
\hline 402 & & of a box around me \\
\hline 403 & Laura & (laughs) \\
\hline 404 & Claire & if I was going near wasps like that (smiling voice) \\
\hline 405 & Laura & (laughs) well he's wearing quite a lot on the his \\
\hline 406 & & hands I know he has gloves on them \\
\hline 407 & Claire & yeah that's ok $(\ldots)$ \\
\hline 408 & Laura & a father of one of my friends in Slovakia was a eh \\
\hline 409 & & what's it called the bee sting so he was he has \\
\hline 410 & & been stung? \\
\hline
\end{tabular}

Laura's question in line 390 about that one obviously refers to a photo in the paper, and Claire's answer describes what the person in the picture is doing. It is not clear whether Laura's follow-up to the answer is a request for clarification or confirmation, but Claire's yeah in line 395 treats it as a request for confirmation. She then provides a frank assessment which is very briefly acknowledged by Laura. There is then a significantly long pause, which more often than not would signal that this topic is not going anywhere. Unusually, though, Claire pursues the same topic in line 400 by expressing her opinion on the dangers involved in going near wasps without a great deal of protection. Laura laughs at her comments, and a smile can be heard in Claire's voice when she continues in line 404, indicating that they share similar perceptions of the event. Laura points out that he is at least wearing gloves, and this is her first substantial comment on the topic, an indication that she is now collaborating in establishing this topic. Claire concedes the point, and in line 409 Laura starts the beginning of a related anecdote, so shows an ability to develop a 'setting talk' topic into a more substantial one.

\section{Disjunctive topic changes}

This type of topic change falls at the extreme end of the scale of non-coherence, as the new topic which is introduced is not only entirely disconnected from any topic in the previous talk, either immediately previous utterances or earlier in the conversation, but there is also a complete lack of boundary makers, such as pauses or other signs that the previous topic has been closed.

A further distinguishing feature of this type of change, as found in this study, is that it is the current speaker who initiates the change of topic. No speaker change is involved, but the topic is changed within the current speaker's turn. In one sense all topic changes (and transitions) are collaborative, as a topic initiation will not get off the ground unless the 
recipient shows signs of finding it acceptable or interesting. As West and Garcia (1988:552) point out "...shift work is largely a collaborative accomplishment - the result of speakers' joint activity or inactivity." In their study of such shift work, which focused on topic changes in male-female conversations, they did, however, find evidence that some changes were unilateral (and most frequently employed by males). Ainsworth-Vaughn (1992) in her study of topic transitions in patient-physician interviews links unilateral transitions to issues of power and control, saying that "... unilateral topic transitions are assumed to allocate power to the speaker." (ibid:409). Both West and Garcia and Ainsworth-Vaughn class such unilateral changes as sudden, disjunctive topic changes which have no connection with previous talk, and which also failed to acknowledge, or even interrupted, contributions by the current speaker. The unilateral changes which are described in the following extracts differ in that they are initiated by the current speaker. There were only two instances of such clear-cut disjunctive topic changes in the conversations, and the first one can be seen in the extract below. The topic change comes towards the end of the conversation, when talk has been about the long hours worked by Will's friend.

\section{Extract 12 Fay (NNS) Will (NS)}

808 Will so I think she's well well over thirty hours ( $x x x$ xxx ) thirty-eight

809 hours is your full-time so I think she's ( ) probably at at the

$810 \rightarrow$ full-time hours I'm sure (xxx xxx ) Are we running out of tape ?

811 Fay no it's=

812 Will =I hope she finds this interesting

813 Fay yeah well I just ( ) hope it'll work good

In line 810 he suddenly switches topic and asks Are we running out of tape? This might have been in response to a gesture or look by Fay, or indeed for a desire for the tape to come to an end. There may be some support for this interpretation, as Fay's response which starts with a $n o$, is latched by Will's comment on the possible interest to the researcher. In return Fay expresses her hope that the tape will work good, and at this point the tape recorder is switched off. Below is the second instance where there was seemingly nothing to signal the coming of a change of topic.

\section{Extract 13}

341

342

345

346

$347 \rightarrow \quad$ Laura

348

349

350

\section{Laura (NNS) Claire (NS)}

and on Saturdays it's till mid- midday and then it's (..)

oh but not in Germany they don't don't open on

Sundays in Slovakia the big the big market stores=

=yeah $=$

$=$ are open on Sundays You are starving and you are

(xxx xxx) only half of it

Claire yeah but I've gone past you know when you haven't=

Laura $=$ uh

Laura and Claire have been comparing opening hours of shops and clubs in their respective countries, when, in line 347, Laura's attention is seemingly diverted by something happening in the immediate environment. Audio-recordings, unfortunately, do not reveal the physical actions, gestures or facial expressions which can say as much as language in a conversation, and it is therefore not possible to guess what may have caused this switch in attention from the opening hours of shops to Claire's half-eaten pizza. It is possible that 
Claire had at some point earlier in their talk referred to 'being starving', maybe while the tape recorder was switched off. Laura's remark is other-oriented, showing interest in her conversational partner. Although her topic initiation is framed as a statement, it contains an implied question, and so requires a response. Claire's yeah and subsequent explanation in line 349 signal her acceptance of the remark as an appropriate one at this point in the talk, and in fact the talk soon moves on to a discussion of pizza preferences. This is in itself an unusual outcome of what is effectively setting talk, as such topics generally tend to be rather shortlived. Maynard and Zimmerman (1984:304) refer to setting talk as "a 'false topic' in the sense that it is quickly exhausted...", and Svennevig (1999:216) observes that "setting talk may have a transitional character in that it is regularly used as an intermediary for entering into other topics." This seems to be in accord with the general discourse pattern which prevails in this conversation, where several extended topics emerge out of talk which refers to on-going activities. All other instances of marked topic changes relating to setting talk contained at least minor indications that there was an opportunity for introducing new matters into the talk, or provided some indication or justification for such a change, and besides they were instances where the topic change occurred as a result of speaker change.

\section{Discussion and conclusions}

This article has drawn attention to some of the discourse strategies involved in managing the closure of topics, and the introduction and establishment of new topics in NS-NNS conversations. It should be stressed that no generalisations can be drawn about the nature of NS-NNS interactions from the findings of this research, as the comparatively small number of participants involved cannot in any way be taken to be representative of the vast numbers of NNSs across the world who successfully communicate in a foreign language.

The types of abrupt or disjunctive topic changes thought to be associated with NS-NNS conversations were not prevalent in the conversations. On the few occasions when they did occur, they did not appear to cause any difficulties for the conversation partners as the topic was taken up and immediately responded to. Because these topic initiations were related to the situations or settings which the participants shared, appropriate responses were easy to provide; there was no need to explicitly signal a change, because the context provided for understanding. Both the physical presence of items referred to, and quite likely also body language like eye gaze and pointing would help to draw attention to the new topic. Marked topic changes were either the result of a previous topic being closed down, with appropriate signals of impending closure, or they related to the current activity which participants were involved in, and therefore maintained an element of global coherence in the conversation. They did not, therefore, 'come out of the blue', and were not employed because the NNS participants were unable to continue talking, or unable to manage effective topic shifts.

Although the study did not look specifically at topic dominance or control, in spite of this also being an area where NNSs are thought deficient, the analysis of topic changes and topic initiations indicated that these were as likely to be effected by NNSs as by NSs. Indirectly, therefore, this would suggest active participation and shared responsibility on the part of the NNSs; they did not, in other words, need to rely on their NS partners to introduce new topics into the conversations. Analysis of the data also indicated that what Steensig and Drew (2008:7) refer to as the 'controlling' force of questioning was shared equally in the topic initiations in these conversations. The appearance of "question-answer sequences" referred to by Long (1983:133) as typical of NS-NNS conversation was the exception rather than the rule in the conversations, and related to the nature of the conversations rather than to the linguistic skills of the NNS participants.

There were no discernible patterns or differences with regard to either NS or NNS frequency or strategies for initiating disjunctive or marked topic changes. What was 
noteworthy, though, was the fact that there were comparatively few topic changes overall in the conversations, and that there was no evidence to suggest that NNSs resort to either abrupt or frequent topic changes. Moreover, they showed themselves able to participate equally and effectively in the management of topic changes. The overall tendency in these conversations was to employ topic transitions rather than changes to initiate new topics, that is, to incorporate an element, a comment or response to a previous utterance while at the same time introducing new or related matters into the talk. This had the effect of maintaining continuity and coherence in the talk, and it was a feature which was used equally by NSs and NNSs. Maynard (1980:284) described the ability to change topics easily and quickly in social conversation as "no mean thing", and these NNSs demonstrated some considerable skill in attending to all the multi-dimensional aspects of topic shifting, at the structural, interpersonal and content levels. The findings may therefore contribute to a more positive view of the conversational competence of non-native speakers.

Topic management is a very complex area, and one which merits far more research, particularly as it is played out in conversations between native and non-native speakers. While this investigation has only been able to provide an indication of how some NNSs manage the processes of moving from one topic to another in conversations, it will add to existing knowledge about NS-NNS interactions, particularly with regard to non-institutional, naturally occurring talk. It is an area of discourse which is of crucial importance for successful interpersonal and intercultural interactions, and hence one which could be expected to be on the agenda for second language learners in classrooms contexts. Discourse management, however, tends to be noticeably absent from language course books and language classrooms. Kramsch (1987:3) argues that "If students are to take an active part in interactions, they must be shown how to control the way topics are established, built and, sustained". Savignon and Sysoyev (2002:513) similarly stress that "Learning how to shift the subject of the discussion to another topic gives students an additional resource." It is therefore an aspect of language learning which deserves more attention in classrooms.

Whether NNSs acquire discourse skills from participation in informal interactions would be a worthwhile area for further research. Nakamura et al (2008:266) suggest that "Looking at informal (i.e. non-instructional) dyadic talk outside of the classroom offers us a unique and extended glimpse into how talk is co-constructed", and such investigations would offer an opportunity to expand the framework of research into both second language acquisition and intercultural communication.

\section{References}

Abu-Akel, A. 2002. The psychological and social dynamics of topic performance in family dinnertime conversation. Journal of Pragmatics 34:1787-1806

Ainsworth-Vaughn, N. 1992. Topic Transition in Physician-Patient Interviews: Power;

Gender and Discourse Change Language in Society 21/3:409-426

Atkinson, J. M. and Heritage, J. (eds) 1984. Structures of Social Action

Cambridge University Press

Bolden, G.B. 2006. Little Words that Matter: Discourse Markers "So" and "Oh" and the

Doing of Other-Attentiveness in Social Interaction Journal of Communication 56/4:661-688 
Broe. V. 2003. Skip-connecting as a means for maintaining coherence - an aspect of the sequential organisation of talk. Acta Linguistica Hafniensa: International Journal of Linguistics, 35/1:160-185

Brown, G. and Yule, G. 1983. Discourse Analysis Cambridge University Press

Bublitz, W., Lenk, U., Ventola E. (eds.) 1999. Coherence in Spoken and Written Discourse.

Amsterdam: John Benjamins

Carter, R. and McCarthy, M. 1997. Exploring Spoken English Cambridge University Press

Egbert, M. 2005. Discrimination due to Nonnative Speech Production? Ch. 11 in Richards, K. and Seedhouse, P. 2005. Applying Conversation Analysis. Basingstoke: Palgrave Macmillan. Fung, L. and Carter, R. 2007. Discourse Markers and Spoken English: Native and Learner Use in Pedagogic Settings Applied Linguistics 28/3:410-439

Garrod, S. and Pickering, M.J. 2004. Why is conversation so easy?

Trends in Cognitive Sciences Volume 8, Issue1, pp. 8-11

Gardner, R. and Wagner, J. (eds.) 2005. Second language Conversations London:

Continuum

Geluykens, R. 1997. It Takes Two to Cohere: The Collaborative Dimension of Topical Coherence in Conversation In Bublitz et al (eds)

Glenn, P.J. 2003. Sex, Laughter and Audiotape: On invoking Features of Context to Explain Laughter in Interaction In Glenn, Lebaron and Mandelbaum (eds) Studies in Language and Social Interaction

Holt, E. 2010. The last laugh: Shared laughter and topic termination. Journal of Pragmatics, 42/6:1513-1525

Howe, M. 1991. Collaboration on Topic Change in Conversation

Kansas Working Papers in Linguistics, Volume 16 University of Kansas

Itakura, H. 2001. Describing conversational dominance Journal of Pragmatics 33:18591880

Itakura, H. 2002. Gender and Pragmatic Transfer in Topic Development

Language, Culture and Curriculum15/2:161-183

Iwata, Y. 2010. Pragmatic failure in topic choice, topic development, and self-disclosure in Japanese EFL speakers. Intercultural Communication Studies XIX/2:145-157

Jefferson, G. 1984. On the organization of laughter in talk about troubles. In

Atkinson, J. M. and Heritage, J. (eds) 1984. Structures of Social Action

Cambridge University Press

Kramsch, C.J. 1987. Interactive discourse in small and large groups In Rivers,W.M.(ed.)

Interactive Language Teaching. Cambridge University Press. 346-69.

Lenk, U. 1998. Discourse markers and global coherence in conversation Journal of

Pragmatics 30: 245-257

Long, M.H. 1981 Questions in foreigner talk discourse Language Learning 31/1:135-157

Long, M. H. 1983 Native speaker/non-native speaker conversation and the negotiation of comprehensible input Applied Linguistics 4/2: 126-141

Maynard, D.W. 1980. Placement of Topic Changes in Conversation Semiotica 30/3:263290

Maynard, D. W. and Zimmerman, D. H. 1984. Topical Talk, Ritual and the Social

Organization of Relationships Social Psychology Quarterly 7/4: 301-316

Meierkord, C. 2000. Interpreting successful lingua franca interaction.

Linguistik online 5, 1/00 Accessed 26/09/2007 from: http://www.linguistik-online.de

Morris-Adams, M. 2014. From Spanish paintings to murder: topic transitions is casual conversations between native and non-native speakers of English. Journal of

Pragmatics:151-65. 
Nakamura, I. 2008. Understanding how teacher and student talk with each other: An exploration of how 'repair' displays co-management of talk-in-interaction Language Teaching Research 12:265-283

Planalp, S. and Tracy, K. 1980. Not to change the topic but...: A cognitive approach to the management of conversation In Communication Yearbook 4 (Ed. Nimmo,D.) International Communication Association

Raymond, G. 2004. Prompting Action: The Stand-Alone "So" in Ordinary Conversation Research on Language and Social Interaction 2:185-218

Richards. J. C. 1990. The Language Teaching Matrix Cambridge University Press

Richards, K. and Seedhouse, P. 2005. Applying Conversation Analysis. Basingstoke: Palgrave Macmillan.

Savignon, S. and Sysoyev, P. 2002. Soicocultural strategies for a dialogue of cultures Modern Language Journal 86:508-524

Schiffrin, D. 1987. Discourse Markers Cambridge University Press

Schwienhorst, K. 2004. Native-Speaker/Non-Native Speaker Discourse in the MOO : Topic negotiation and Initiation in a Synchronous Text-Based Environment Computer Assisted Language Learning 17/1:35-50

Steensig, J. and Drew, P. 2008. Introduction: questioning and affiliation/disaffiliation in interaction Discourse Studies 10/1:5-15

Stewart, S. 1997. The many faces of conversational laughter.

Paper presented at the Annual Meeting of the Conference on Linguistics and Literature (9t, Denton, TX, February 7-9,1997) Accessed from Eric database 23.02.07

Svennevig, J. 1999. Getting Acquainted in Conversation Amsterdam: John Benjamins Tryggvason, Marja-Terttu 2004. Comparison of Topic Organization in Finnish, SwedishFinnish, and Swedish Family Discourse Discourse Processes 37/3: 225-248

Viswat, L and Kobayashi, J. 2008. Cultural differences in conversational strategies. Journal of Intercultural Communication 18

West, C. and Garcia, A. 1988. Conversational Shift Work: A Study of Topical Transitions between Women and Men Social Problems 35/5:551-575

Wong, J. 2005. Sidestepping Grammar. Ch. 10 in Richards, K. and Seedhouse, P. 2005. Applying Conversation Analysis. Basingstoke: Palgrave Macmillan. 